
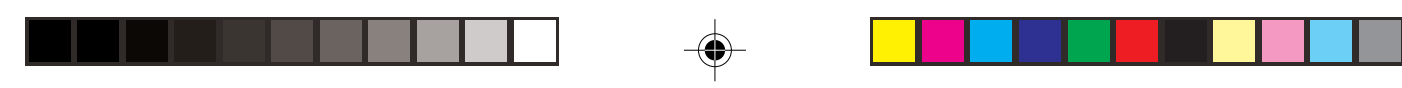

ISSN 1518-3483

Licenciado sob uma Licença Creative Commons

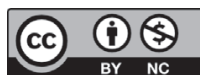

\title{
A DOCÊNCIA UNIVERSITÁRIA DO PONTO DE VISTA DO TRABALHO E DO RECRUTAMENTO DE NOVOS PROFES- SORES NA ERA ATUAL EM QUEBEC ${ }^{1}$
}

\section{L'enseignement universitaire sous l'angle du travail et du recrutement de nouveaux professeurs au Québec}

\section{Cecília Borges}

Pesquisadora regular do Centre de recherche sur la formation et la profession enseignante Universidade de Montreal (CRIFPE), Montreal, Quebec, Canadá, e-mail: cecilia.borges@umontreal.ca

\footnotetext{
Este texto foi produzido inicialmente no quadro de uma conferência realizada na UNESP de Rio-Claro por ocasião do III Seminário de Estudos e Pesquisas em Formação Profissional no Campo da Educação Física e intitulado: "A DOCÊNCIA UNIVERSITÁRIA E A EDUCAÇÃO FÍSICA", de 29 a 31 de março de 2007.
}

Rev. Diálogo Educ., Curitiba, v. 10, n. 29, p. 59-84, jan./abr. 2010 


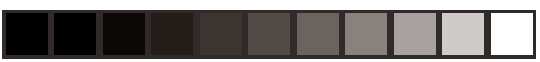

60

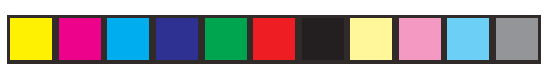

BORGES, C.

\section{Resumo}

O texto aborda a problemática da docência universitária em Quebec, particularmente em relação ao trabalho e ao recrutamento de professores. Com base em estudos realizados pela Federação Quebequense de Professoras e Professores das Universidades Quebequenses, pela Conferência de Reitores das Universidades Quebequenses, pelo Conselho Superior de Educação, entre outros, apresenta um panorama dos desafios à serem enfrentados quanto à renovação do corpo docente nas Universidades, em Quebec, nas próximas décadas. Enfatizando as transformações pelas quais vêm passando o trabalho docente universitário assim como o seu impacto na pessoa do docente e na capacidade das universidades de renovação do corpo professoral, o texto explora as questões do recrutamento com os doutorandos, da inserção dos professores novos na carreira e das exigências acadêmicas em relação às diferentes tarefas que compõem o trabalho do docente universitário. À guisa de conclusão, aponta pistas relativamente às condições de trabalho consideradas necessárias a atrair, mas sobretudo a reter os professores novos na profissão como: melhor equilíbrio entre as tarefas docentes, conciliação trabalho-família, incentivos financeiros, entre outros.

Palavras-chave: Docência universitária. Ensino superior. Professores debutantes. Carreira universitária. Trabalho docente.

\section{Résumé}

Le texte aborde la problématique de l'enseignement universitaire au Québec, plus particulièrement en relation avec le travail et le recrutement des professeurs. Prenant appui sur des études réalisées notamment par la Fédération québécoise des professeures et professeurs des universités du Québec, par le Conseil supérieur d'éducation, par la Conférence des recteurs et des principaux du Québec, il présente un panorama des défis que les universités doivent relever par rapport au renouvellement du corps professoral au Québec dans les prochaines décennies. En mettant l'accent

Rev. Diálogo Educ., Curitiba, v. 10, n. 29, p. 59-84, jan./abr. 2010 

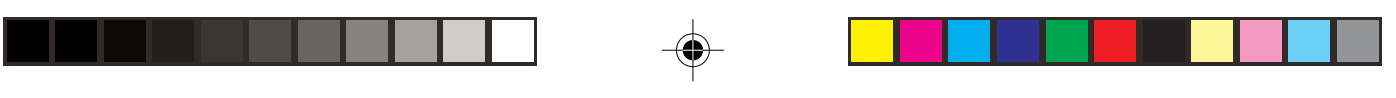

A docência universitária do ponto de vista do trabalho e do recrutamento de novos professores na era atual em Quebec

sur les transformations qui affectent actuellement le travail professoral universitaire et leurs impacts sur la personne du professeur lui-même ainsi que sur la capacité des universités à renouveler leur corps de professeurs, le texte explore les questions du recrutement auprès de doctorants, de l'insertion professionnelle des professeurs débutants et des exigences accrues à l'égard de différentes tâches qui composent le travail des universitaires. En guise de conclusion, il indique des pistes relativement à la nécessité d'implanter des conditions de travail capables d'attirer et de retenir les professeurs débutants dans la profession, comme un meilleur équilibre entre les tâches professorales, la conciliation travail-famille, des incitatifs financiers, entre autres.

Mots-clefs: Enseignement universitaire. Enseignement supérieur. Professeurs débutants. Carrière universitaire. Travail enseignant.

\section{INTRODUÇÃO}

Em Quebec, vários estudos apontam a cada ano entre 10 e 20\% de docentes da educação de base (primária e secundária) que abandonam a profissão antes mesmo de completar cinco anos de exercício. Confrontados com a dura realidade de trabalho em contexto escolar como instabilidade de emprego, nomadismo em vários estabelecimentos escolares, clientelas cada vez mais heterogêneas, atribuição de grupos considerados difíceis, isolamento ou falta de apoio da equipe escola e da direção, entre outros, os docentes iniciantes perdem a motivação para persistirem na carreira docente. Esse fenômeno, bem documentado por várias pesquisas, vem incitando tanto pesquisadores como autoridades educativas do Ministério da Educação, das Comissões Escolares e das próprias Universidades a fim de desenvolverem ações visando à inserção e retenção dos docentes iniciantes na profissão.

O problema da inserção e da retenção de professores, contudo, não é uma particularidade da educação básica. Nas última década, esse fenômeno vem sendo igualmente registrado no âmbito da docência

Rev. Diálogo Educ., Curitiba, v. 10, n. 29, p. 59-84, jan./abr. 2010 
universitária. Fazendo parte da categoria de professores iniciantes em contexto quebequense, interessou-me a situação dos professores novos ou iniciantes nas universidades, e isto, particularmente neste momento em que as exigências acadêmicas parecem aumentar continuamente.

O objetivo deste texto é abordar a situação dos docentes universitários debutantes na profissão em Quebec, em particular, e na América do Norte, em geral. Inicialmente, apresento as estimativas recentes relativamente à renovação dos quadros docentes nas Universidades quebequenses e canadenses. Em um segundo momento, descrevo as transformações do trabalho docente universitário. Em um terceiro momento, descrevo alguns efeitos dessas transformações sobre o trabalho docente universitário e particularmente sobre o recrutamento de novos professores, isto é, sobre os doutorandos que potencialmente poderão seguir a carreira universitária. Em um quarto momento, apresento os principais resultados de um estudo sobre as preocupações dos professores debutantes (professores novos) e concluo com algumas pistas de reflexão sobre esse processo que parece cada vez mais complexo e que é comum às universidades canadenses e brasileiras. Espera-se com este texto partilhar dados de uma realidade que vem se agravando cada vez mais e preocupando as autoridades sindicais e administrativas implicadas na gestão do ensino superior.

\section{Dados gerais sobre a renovação dos quadros docentes nas Universidades}

Tornar-se professor universitário é provavelmente um sonho acalentado por muitos doutorandos que, ao buscarem a pós-graduação, desejam continuar trabalhando em pesquisa e na formação superior. Ensinar nos ciclos superiores significa para muitos seguir uma paixão por um objeto de estudo mas, também, diz respeito a uma vontade de transmitir essa mesma paixão às futuras gerações no âmbito de um programa de formação profissional. Vários estudos sobre a docência universitária, notadamente sobre os saberes dos docentes universitários, apontam o amor por um campo de estudo, a influência de bons professores, o desejo de continuar em contato com jovens e de contribuir para melhorar a sociedade, como fatores que instigam a escolha da docência universitária. Essa descrição coincide com aquela

Rev. Diálogo Educ., Curitiba, v. 10, n. 29, p. 59-84, jan./abr. 2010 

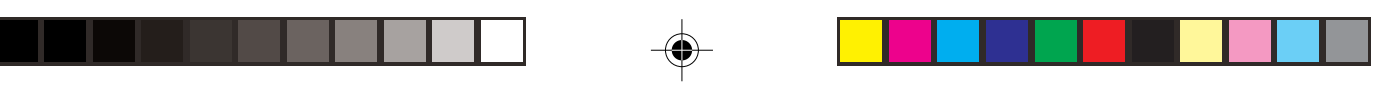

A docência universitária do ponto de vista do trabalho e do recrutamento de novos professores na era atual em Quebec

dos docentes de ensino fundamental quando questionados sobre os motivos que os levaram a escolher a docência como profissão. Mas o que acontece quando os docentes universitários debutantes que, como seus homólogos da educação básica, deixam a profissão já nos primeiros anos de trabalho, muitas vezes às vésperas de obterem a permanência no emprego? Quais sãos os motivos que levam estes jovens professores a abandonarem um trabalho atraente, sinônimo de estabilidade no emprego, de bom salário, de férias de um mês, de viagens e participação em congressos científicos, de possibilidade de atuar em um campo de estudos que se encontra na origem da escolha da profissão? O que fazer para reter os docentes na profissão, ou melhor, para atrair os doutorandos a persistirem na carreira universitária?

Eis algumas questões na base deste texto, que tem inquietado sobretudo a Federação dos Professores e Professoras das Universidades quebequenses (FÉPPUQ - Fédération des professeurs et professeures des Universités québécoises). Com base em estatísticas recentes, esta federação traça um futuro sombrio da realidade profissional dos novos professores em um relatório intitulado A renovação do quadro professoral em Quebec, perfil e experiencia dos recrutas em inicio de carreira (DYKE, 2006). Os dados apresentados nesse relatório parecem paradoxais se considerarmos que no mesmo documento encontram-se indicadores evidenciando a necessária renovação do quadro docente universitário nos próximos anos.

\section{Mais vagas nas universidades}

Desde o ano 2000, em Quebec e no Canadá assiste-se um movimento importante de renovação do corpo professoral nas universidades que será, sem sobra de dúvida, um dos grandes desafios do século XXI, e isto principalmente considerando-se as mutações anteriores no âmbito dos quadros professorais que persistem ainda hoje.

A década precedente foi marcada particularmente por aposentadorias antecipadas e por um congelamento de contratações por causa dos cortes orçamentários nas universidades (não transferência de verbas do Governo Federal às províncias para o ensino póssecundário e política do déficit zero na província de Quebec). Assim, entre 1994 e 1999, o corpo professoral das universidades baixou de $11,5 \%$ e os efeitos dessas políticas se fazem sentir até recentemente.

Rev. Diálogo Educ., Curitiba, v. 10, n. 29, p. 59-84, jan./abr. 2010 
Em 2001, o Governo de Quebec investiu 300 milhões de dólares nas Universidades de Quebec, enquanto que o Governo Federal decidiu investir nas Chaires $^{2}$ de pesquisa, na criação da Fundação canadense pela inovação entre outras medidas indiretas para relançar o setor (como desenvolvimento de laboratórios e de infraestrutura). Isto, no entanto, não diminuiu as carências relativamente à falta de professores para preencher as vagas deixadas pelas aposentadorias. Além disso, em 2003, um estudo da Conferência de reitores das Universidades de Quebec (CREPUQ) ${ }^{3}$ estimava que as universidades apresentavam um déficit de 375 milhões de dólares.

Em 2003, o Conselho superior da educação estimava recrutar uma média de 614 professores por ano até 2008 para resolver o problema da falta de professores. O CREPUQ, por sua vez, havia indicado a necessidade de contratar em média 1.067 professores, mas esse número era ainda insuficiente, pois as aposentadorias continuaram depois de 2001. Desde 2001, uma média de 665 professores por ano foi contratada, todavia, esse número é insuficiente, considerando-se que 6,5\% dos professores partem a cada ano. Atualmente, estima-se ainda necessidade de contratação de 1340 professores suplementares.

Esses números indicam um quadro favorável para os futuros doutores que desejam ingressar na carreira universitária docente. Todavia, sabe-se que o movimento de recessão no setor persiste, pois para cada duas ou três aposentadorias, apenas uma vaga tem sido preenchida. O quadro geral é assim mesmo positivo, já que os departamentos universitários, assim como os sindicatos, continuam a lutar pela abertura de novas vagas.

Finalmente, fora esses números surpreendentes, é importante notar que a renovação do quadro professoral atual dá-se em um contexto diferente do passado, visto que a carreira do docente universitário tem passado por inúmeras transformações nos últimos vinte anos, e isto, quanto à missão universitária, às exigências e responsabilidades e à carga de trabalho dos docentes.

\footnotetext{
Cátedras de pesquisa.

Conférence des recteurs et des principaux des universités du Québec (CREPUQ).
}

Rev. Diálogo Educ., Curitiba, v. 10, n. 29, p. 59-84, jan./abr. 2010 

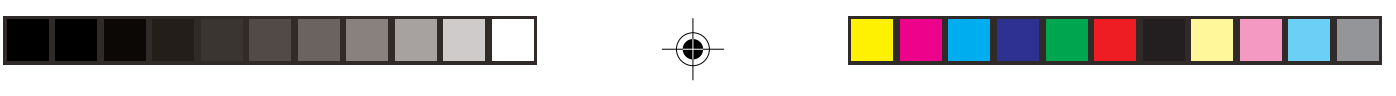

A docência universitária do ponto de vista do trabalho e do recrutamento de novos professores na era atual em Quebec

\section{As transformações no trabalho docente universitário}

\section{Descrição do trabalho do professor}

Em Quebec, mas igualmente no Canadá, o trabalho do professor universitário se define segundo quatro $\operatorname{campos}^{4}$ de atuação: ensino, pesquisa, irradiação ${ }^{5}$ social e participação à vida universitária, os quais servem de referência para a avaliação funcional do docente (obtenção da permanência e titularidade). Evidentemente, espera-se que esses quatro campos convirjam uns em relação aos outros, mas os dois primeiros assumem uma importância maior no âmbito da carreira universitária atualmente. Dito de outra forma, ao menos em teoria, busca-se a indissociabilidade entre esses diferentes eixos com uma articulação particular entre ensino e pesquisa. A irradiação social, quanto a ela, decorre normalmente da visibilidade do trabalho do professor na comunidade, através de projetos com a comunidade, da participação em comitês ou associações científicas, de comunicações em congressos nacionais e internacionais, enfim, de ações que contribuem ao desenvolvimento social e científico do seu campo mas, sobretudo, que dão visibilidade à instituição de origem do professor. Quanto à vida universitária, ela se refere principalmente às atividades departamentais e universitárias, à participação em comitês universitários, bancas de concursos, cargos de chefia, etc.

A carga de trabalho de um professor, com algumas variações de uma universidade para outra, corresponde normalmente a 40 horas semanais, com dedicação exclusiva. A fim de conservar justo equilíbrio entre as diferentes tarefas, um professor deve assumir anualmente quatro disciplinas (cursos) na graduação ou pós-graduação. Cada curso perfaz um total de 45 horas, três créditos, 12 créditos por ano no total. O resto de seu tempo é dedicado às demais tarefas universitárias relativas ao ensino, como orientação e enquadramento de estudantes, bancas de teses e de mestrados, supervisão de profissionais de pesquisa,

4 Como os eixos de atuação de um professor universitário não diferem muito de um país para outro, não nos ocuparemos em detalhar a descrição destes.

5 Trata-se de rayonnement social, visibilidade acadêmica, reconhecimento social internamente e externamente à universidade.

Rev. Diálogo Educ., Curitiba, v. 10, n. 29, p. 59-84, jan./abr. 2010 
etc. e, particularmente, à pesquisa, visto que uma das principais responsabilidades do docente universitário é a de desenvolver o seu campo de conhecimento por meio da pesquisa subvencionada e da produção científica, cultural ou artística.

Em relação à pesquisa, em Quebec, dois grandes organismos governamentais estão na base das demandas de subvenção: o Conseil de recherche en sciences sociales et humaines (CRSH) ${ }^{6}$ do governo federal e o Fonds québécois de recherche de la société et de la culture (FQRSC) ${ }^{7}$. Algumas universidades possuem um fundo de apoio para professores iniciantes, outras possuem fundos internos para o desenvolvimento da pesquisa e do ensino. Além disso, cada vez mais os professores são encorajados a buscarem subvenções externas, no âmbito da iniciativa privada ou pública, como ministérios públicos, empresas, organizações não governamentais, associações, sindicatos, comissões escolares, entre outras.

\section{As transformações do trabalho dos professores universitários}

Como a sociedade, a Universidade vem passando por inúmeras transformações. Estas decorrem do que vem sendo chamado de Sociedade da Economia e do Saber, a qual exerce uma pressão considerável sobre as universidades quebequenses. Mais especificamente, a pressão decorre, segundo Saint-Pierre (2008):

a) de grupos diversos, com interesses às vezes contraditórios, os quais criam uma tensão em torno da definição e da missão da universidade;

b) do desenvolvimento rápido da sociedade do saber acoplada à economia do saber que transforma a universidades em instituições estratégicas quanto à inovação e à produção de conhecimentos que respondam aos desafios econômicos, sociais e culturais atuais;

c) da necessidade de garantir o acesso ao ensino superior a um número crescente de estudantes que, a cada ano, buscam o

\footnotetext{
Conselho de pesquisa em ciências sociais e humanas.

Fundo quebequense de pesquisa da sociedade e da cultura.
}

Rev. Diálogo Educ., Curitiba, v. 10, n. 29, p. 59-84, jan./abr. 2010 

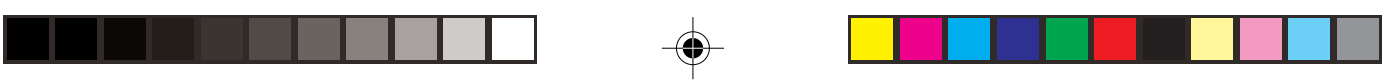

A docência universitária do ponto de vista do trabalho e do recrutamento de novos professores na era atual em Quebec

ensino superior e, nessa mesma direção, de preservar as taxas escolares atuais que são, aliás, as mais baixas do Canadá e da América do Norte ${ }^{8}$, atraindo assim inúmeros jovens de outras províncias e/ou países para as instituições universitárias quebequenses;

d) do declínio demográfico da população quebequense, o qual tem impacto sobre o financiamento das Universidades regionais, notadamente quanto à capacidade destas em manter um leque variado de programas de formação profissional;

e) do impacto das políticas econômicas sobre a orientação universitária (volume de financiamento e objetos de pesquisa à serviço da inovação, da ciência e da tecnologia);

f) enfim, da capacidade dos governos federal e provincial para responderem às demandas das universidades e da educação básica de um modo geral.

Vistas como polos privilegiados de produção e de transmissão de conhecimentos, as Universidades devem compor ao mesmo tempo com um contexto de crise, no qual os recursos tendem a diminuir e a responsabilidade de gestão assim como a capacidade de autofinanciamento é transferida aos gestores, à própria administração universitária e, por extensão, aos professores e quadros universitários. Nos últimos anos, por exemplo, observa-se uma intensificação e também "precarização" do trabalho dos docentes que devem compor com:

a) redução de verbas para o funcionamento de suas atividades regulares como contratação de auxiliares de ensino, ou de assistentes para a correção dos exames acadêmicos, ou ainda, diminuição de recursos materiais como papel, fotocopias, telefone, entre outros;

b) diminuição do pessoal de apoio técnico (serviço de secretariado, técnico administrativo, entre outros) nos diferentes departamentos;

8 É importante notar que o financiamento das Universidades Canadenses e quebequenses é grandemente público, ainda que sejam cobradas taxas de matrícula aos estudantes. As Universidades são neste sentido públicas, mas pagas.

Rev. Diálogo Educ., Curitiba, v. 10, n. 29, p. 59-84, jan./abr. 2010 


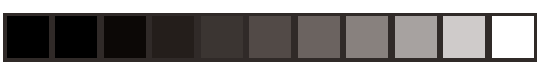

68

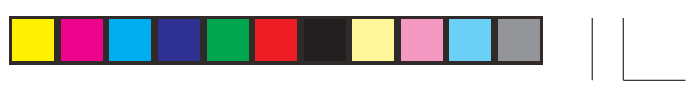

BORGES, C.

c) aumento do número de alunos por disciplina, por exemplo, grupos de 100 ou mais alunos;

d) diminuição do número de contratações; em certos casos, para cada duas, ou três aposentadorias, somente um professor novo é contratado. Aliás, cada vez mais as universidades fazem apelo aos encarregados de cursos, que, como os professores substitutos no Brasil, não fazem parte do quadro da carreira docente. Além disso, fala-se mesmo de uma nova categoria de profissionais docentes que serão contratados sem a possibilidade de obterem a permanência na vaga;

e) aumento das exigências acadêmicas em termos de avaliação da produtividade docente, que responsabilizam o professor pela busca de recursos financeiros para a pesquisa especialmente e mesmo para o ensino, e ainda, pela demonstração de sua capacidade de produzir academicamente e de recrutar alunos.

Em relação a este último aspecto, é importante notar, ainda, que os professores são chamados a fazer face à crise, aumentando o número de alunos inscritos na pós-graduação sob seu enquadramento, principalmente no âmbito do doutorado, cuja cota de financiamento é superior à graduação, ao mestrado profissional e ao mestrado com ênfase na pesquisa respectivamente. O que não é muito distante de uma óptica clientelista, aja vista os investimentos cada vez maiores das universidades em publicidade.

Por sua complexidade atual, constata-se, enfim, que a inovação assim como a articulação entre ensino e pesquisa vai tornando-se cada vez mais frágil pela fragmentação e intensificação das tarefas docentes (orientar alunos, preparar e ministrar aulas, corrigir trabalhos, publicar, participar de comitês, realizar comunicações científicas, participar de bancas, etc.) e da incessante busca por financiamento; os professores frequentemente se voltam para onde os recursos são mais generosos, investindo sistematicamente na participação de concursos altamente concorrenciais como das agências de subvenção governamentais ou

\footnotetext{
Todavia, uma diferença entre os encarregados de cursos (chargés de cours) e os professores substitutos, é que os primeiros possuem certa estabilidade; organizados em torno do sindicato dos encarregados de cursos, após três anos de "probação", estes adquirem prioridade no ensino de uma disciplina sob a sua responsabilidade.
}

Rev. Diálogo Educ., Curitiba, v. 10, n. 29, p. 59-84, jan./abr. 2010 

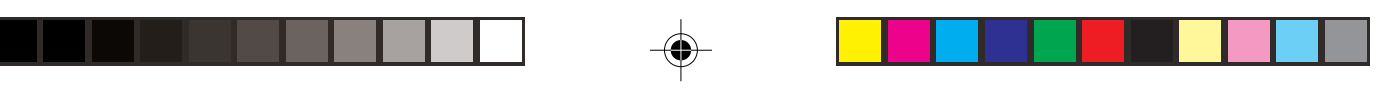

A docência universitária do ponto de vista do trabalho e do recrutamento de novos professores na era atual em Quebec

respondendo às chamadas de particulares que financiam projetos que nem sempre convergem com as orientações e princípios universitários.

Dyke (2006), que citamos no início deste texto, chama a atenção para o impacto da diminuição do financiamento das universidades sobre a liberdade acadêmica dos professores, suas condições de trabalho e, por extensão, sua missão na Universidade. Segundo ela, a busca contínua de financiamento cria redes estratégicas para responder às orientações dos organismos de fomento à pesquisa, obriga o professor a cada vez mais definir o seu trabalho em função de pressões externas ao meio e à comunidade de pesquisadores, e contribui de uma certa maneira à deterioração das relações entre os docentes universitários, os quais, ao invés de desenvolver um clima de cordialidade e coleguismo, entram em competição uns com os outros.

O paradoxo dessa situação é que, sendo a universidade um bem público que tem por função promover o acesso ao conhecimento ao maior número possível de pessoas da população, formar profissionais, promover o bem social e desenvolver a função crítica, livre de relações de poder e de pressões de toda ordem, ela própria abriga práticas que contradizem a sua própria essência e repercutem sobre a qualidade dos serviços oferecidos.

\section{Efeitos das transformações do trabalho do docente universitário sobre a renovação dos efetivos professorais}

Bertrand (2004 apud Dyke, 2006) sublinha que as transformações pelas quais vem passando o trabalho docente universitário decorrem da intensificação das tarefas docentes, da sobrecarga de trabalho, assim como da desvalorização do ensino de primeiro ciclo (graduação) que afetam boa parte dos professores regulares. A articulação entre as tarefas de ensino, pesquisa e serviço à comunidade (interna e externa) tornou-se cada vez mais difícil de atingir, como se o trabalho professoral tivesse evoluído em direção de uma fragmentação cada vez maior, a ponto de deslocar o vínculo essencial entre pesquisa e ensino, que é primordial à qualidade do conjunto dos serviços universitários.

Em seu estudo sobre a renovação do quadro professoral em Quebec, Dyke (2006) indica que as transformações do trabalho docente universitário atuais têm um impacto visível sobre a carreira mas,

Rev. Diálogo Educ., Curitiba, v. 10, n. 29, p. 59-84, jan./abr. 2010 
particularmente, sobre a pessoa do docente. De acordo com os resultados de seu estudo, a prescrição de antidepressivos pelos médicos aos professores é frequente e 4,6\% de pedidos de consulta dos assegurados universitários, dos planos de saúde coletivos, é de ordem psicológica. De 2001 para cá, salienta Dyke (2006), 55\% das causas de invalidade docente são por problemas do sistema nervoso e sensorial, pois muitos professores não resistem à sobrecarga de trabalho e adoecem. E isso ocorre principalmente nos primeiros anos da carreira, quando o professor ainda não goza de estabilidade no emprego e se encontra em posição frágil em relação ao seu trabalho.

Além do aumento de problemas de saúde entre os docentes, outro efeito da intensificação e "precarização" do trabalho universitário é a escassez de candidatos à docência. Nos últimos anos, apesar da demanda crescente por professores, um número cada vez menor de doutorandos (candidatos por excelência ao preenchimento das vagas vacantes) aspira a carreira universitária. Em seu estudo, Dyke (2006) evidencia dados alarmantes nesse sentido, segundo ela, ainda que o número de estudantes de doutorado tenha aumentado, quase 50\% não concluem suas teses e apenas 30\% escolhem a carreira universitária como profissão. Isso significa que a crise no modelo universitário intensifica a situação de penúria em relação à renovação do efetivo docente.

Outro problema identificado pela autora é a falta de uma orientação específica nos diferentes programas de doutorado à preparação para a carreira professoral universitária, como tem sido feito nos Estados Unidos. Ainda que em Quebec identifica-se atualmente uma certa forma de socialização profissional, pautada em estratégias individuais e distintas de um setor a outro, não há como no país vizinho programas nos quais, paralelamente à formação doutoral, prepara-se os doutorandos para a vida e tarefas docentes.

\section{Formar doutores para renovar o quadro docente das universidades: um desafio}

Formar novos doutores para garantir o fluxo de renovação das vagas nas universidades é hoje uma missão complexa. Nós últimos anos, o aumento das exigências acadêmicas no momento da contratação de um professor tem gerado novos desafios para aqueles que desejam

Rev. Diálogo Educ., Curitiba, v. 10, n. 29, p. 59-84, jan./abr. 2010 

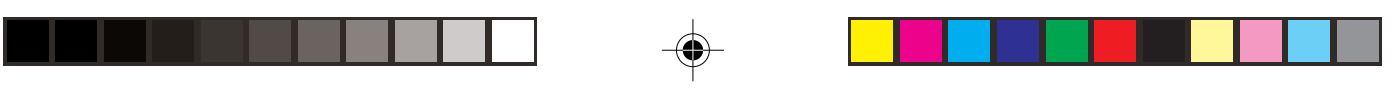

A docência universitária do ponto de vista do trabalho e do recrutamento de novos professores na era atual em Quebec

se engajar nessa via. Não só na América do Norte, mas também em diferentes países da Europa tem-se discutido a cerca:

a) da duração dos estudos, de forma que se consiga reduzir o tempo de escolaridade e de produção da tese. Segundo o Conselho Nacional dos Ciclos Superiores de Quebec, entre 60 e $65 \%$ dos doutorandos abandonam o doutorado durante a fase de redação da tese, isto é, após quatro ou cinco anos de estudo, representando assim uma perda importante para as universidades. Nesse sentido, existe hoje uma grande pressão para que os candidatos ao doutoramento concluam seus estudos em três ou no máximo quatro anos. Aliás, as bolsas para doutoramento cobrem três anos e excepcionalmente quatro anos de estudos. O problema é que as causas do abandono resultam muitas vezes do próprio suporte que o doutorando recebe da Universidade, segundo a Associação Canadense para os Estudos Superiores (2003, apud DYKE, 2006), as razões mais frequentes que levam estudante a abandonar o doutorado são: o financiamento insuficiente; a falta de supervisão construtiva; a concepção inadequada dos programas; o isolamento; as ambições amplas do objeto da tese; e, enfim, a falta de preparação para os estudos superiores.

b) do financiamento dos estudos de pós-graduação. As universidades em muitos países como no Canadá, e particularmente na província de Quebec, buscam cada vez mais atrair novos estudantes para o doutorado. Essa estratégia resulta do plano governamental que subsidia a universidade por cada aluno que se inscreve em um programa de graduação e/ ou de pós-graduação, sendo que o doutoramento é superior em termos de subsídios em relação ao mestrado. Todavia, engajar-se em um doutorado significa igualmente um grande investimento da parte do estudante. Como as universidades são pagas, os estudantes devem eles próprios financiar seus estudos, a menos que este tenha recebido uma bolsa governamental para financiar a sua formação. Em muitos casos, na ausência de uma bolsa, os estudantes optam por empréstimos bancários, assim, um estudante que passou

Rev. Diálogo Educ., Curitiba, v. 10, n. 29, p. 59-84, jan./abr. 2010 


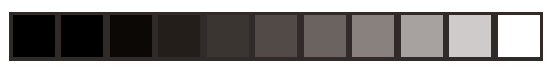

72

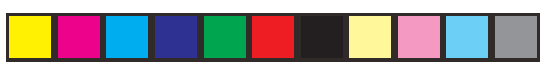

BORGES, C.

toda a sua formação, desde a graduação, fazendo empréstimos bancários, corre o risco de, ao final de seu doutoramento, encontrar-se endividado. 44\% dos titulares de um doutorado, segundo Estatística Canadá (2004), declararam ter contraído dívidas relacionadas aos estudos, no momento da obtenção do diploma. Daí o interesse em encontrar rapidamente um emprego a fim de saldar a dívida adquirida durante sua formação universitária.

c) das novas exigências em relação à profissão; ter um doutorado é hoje um requisito de base no momento de engajar um professor. De fato, as exigências têm aumentado gradativamente, assim, não basta ter doutorado, é necessário ter um bom dossiê de publicações, ter participado de pesquisas, ter ensinado na universidade e, em alguns casos, ter um pós-doutorado.

d) do acesso tardio à permanência no emprego; uma vez engajado em uma universidade, depois de um longo processo de formação acadêmica, os novos doutores devem aguardar a abertura de um vaga para começarem a ensinar. Muitos começam como professores encarregados de cursos até se apresentarem em uma vaga que conduza à permanência. Todavia, uma vez sendo admitido por concurso em uma vaga levando à permanência, os novos docentes passam por um período probatório de entre quatro ou cinco anos, dependendo da universidade. Embora curto, esse período pode ser considerado longo se comparado a um emprego na iniciativa privada ou em um organismo público no qual o período probatório é às vezes bem mais curto. $\mathrm{E}$ isso, mesmo considerando que a estabilidade no emprego seja relativa:

e) da difícil conciliação trabalho-família; escolher a carreira universitária significa, enfim, um grande investimento. Esse investimento é de envergadura, e sendo a carreira universitária absorvente, muitos dos novos professores consideram difícil conciliar o tempo do trabalho e o tempo com a família.

Esses problemas são gritantes, salienta Dyke (2006), de forma que o movimento sindical universitário em diferentes países da Europa mas, também, nos Estados Unidos tem pensado sobre a

Rev. Diálogo Educ., Curitiba, v. 10, n. 29, p. 59-84, jan./abr. 2010 

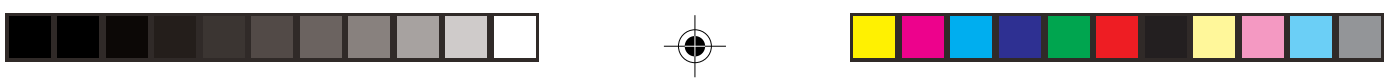

A docência universitária do ponto de vista do trabalho e do recrutamento de novos professores na era atual em Quebec

possibilidade de se considerar o doutoramento como o início da profissão, transformando-o em trabalho remunerado e, em consequência, permitindo acumular pontos para a progressão funcional, tornando mais atraente a profissão Universitária. Sem entrar no debate sobre a pertinência dessas modificações, a autora salienta que essa problemática começou a ser discutida desde 2004 em Quebec, no âmbito da Associação Canadense dos Professores e Professoras Universitário (ACPPU) e da Federação Quebequense dos Professores e Professoras Universitários (FQPPU). Essas duas associações apontam como condições essenciais à carreira:

- a valorização da profissão;

- o apoio importante aos futuros candidatos;

- a definição de critérios de contratação e de acolhida em conformidade com a missão da Universidade;

- o apoio adicional aos professores em exercício;

- um retorno às práticas de gestão mais colegiadas;

- uma valorização do engajamento sindical.

Para além destas constatações, o relatório de Dyke (2006) indica igualmente que há poucos dados sobre a evolução da docência universitária, sua formação e sua socialização profissional. Nesse sentido, seu estudo buscou preencher esta lacuna, isto é, conhecer a nova geração de professores que integra o quadro docente das universidades assim como as exigências atuais e o processo de inserção dos novos docentes.

\section{A nova geração de docentes e sua inserção profisssional}

O estudo de Dyke (2006), ao qual nos referimos seguidamente neste texto, buscou conhecer a situação dos professores novos em início de carreira, isto é, durante os seis primeiros anos de atividade docente universitária que é considerado como período de inserção profissional. Apesar de que muitos dos novos professores engajados possuem experiência, estes são considerados como debutantes na carreira universitária pois, como mencionamos, esta fase é considerada crítica, marcada pela incerteza que antecede a obtenção da permanência na vaga.

Rev. Diálogo Educ., Curitiba, v. 10, n. 29, p. 59-84, jan./abr. 2010 
Os sujeitos participantes do estudo, em torno de 60, são os professores novos de menos de seis anos na carreira docente ${ }^{10}$. Inicialmente, foram utilizados dados de uma enquête do CREPUQ realizada em 2004, especialmente quanto ao perfil sócio-demográfico dos professores. Em um segundo momento, foram realizados grupos de discussão com os professores novos de diferentes estabelecimentos universitários. ${ }^{11}$ Os temas explorados no estudo foram:

a) as preocupações dos professores novos;

b) as modalidades de contratação;

c) a integração no meio de trabalho;

d) a satisfação dos professores em relação ao trabalho;

e) e, enfim, conciliação trabalho-família. Em um terceiro momento, a autora entrevistou diretores de departamentos de Universidades de mais de 500 professores de Quebec a respeito das exigências atuais em termos de contratação de futuros docentes.

\section{Perfil sócio-demográfico dos docentes}

Segundo dados do CREPUQ, em 2004, o pessoal docente das universidades quebequenses compunha-se de 8.765 professores. Desde a retomada do processo de contratação de professores em 2000, uma média de 665 professores por ano foram recrutados. Deste grupo, $20,2 \%$ vêm das ciências humanas, $16,6 \%$ das ciências aplicadas, $13,1 \%$

10 Segundo Dyke (2006), é difícil conhecer o número exato de doutorandos que escolhem a carreira universitária e as enquêtes ministeriais não cobrem a situação dos titulares de um doutorado. No entanto, pela primeira vez na história de Quebec, um estudo foi realizado por Estatística Canadá (2004) a fim de verificar o plano de carreira dos titulares de um doutorado. Este estudo mostrou que apenas 30\% dos doutorandos da Universidade de Toronto, da Universidade de Montreal, incluindo a HEC (École des hautes études comerciales) e Escola Politécnica, preveem continuar no pós-doutorado, enquanto que $55 \%$ desejam entrar diretamente no mercado de trabalho. Enfim, 30\% dos doutorandos de 2003 e 2004 desejam continuar trabalhando em pesquisa e ensino (Estatística Canadá, 2004).

11 Para saber mais sobre este estudo, consultar o relatório Dyke, N. (2006). Renouvellement du corps professoral dans lês Universités em Québec. Profil et expérience de recrues en début de carrière. Fédération Québecoise de professeures et professeurs d'université. Avril, 2006.

Rev. Diálogo Educ., Curitiba, v. 10, n. 29, p. 59-84, jan./abr. 2010 
A docência universitária do ponto de vista do trabalho e do recrutamento de novos professores na era atual em Quebec

das ciências puras e $11,8 \%$ da administração. Esse número, como já mencionamos, é inferior à demanda existente.

Sobre um total de 679 recrutas em 2003, 426 correspondiam ao cargo de adjunto (primeiro nível da carreira universitária em Quebec). A média de idade dos professores é de 38,5\% em 2004, sendo que, em 1993 , esta era de $37,5 \%$. Os grupos etários mais representativos são de 30 a $34 \operatorname{anos}(41 \%)$ e 35 a $39(24 \%)$. As mulheres (39\%) são mais representativas que os homens (28\%). Deste grupo, $79 \%$ são titulares de um diploma de doutorado.

Quanto à origem dos docentes, dados do Conselho Superior de Educação indicam que 31\% dos professores foram recrutados fora do Quebec, particularmente, em âmbito internacional.

Os dados do CREPUQ (2004) indicam enfim que, apesar do saldo positivo, há uma perda significativa de docentes, $29 \%$ dos professores contratados entre 1998 e 2003 abandonaram a carreira, uma perda de $10 \%$ no primeiro ano e de $30 \%$ após cinco anos.

\section{Principais resultados do estudo sobre a situação dos professores novos}

As trajetórias que conduzem à carreira universitária são variadas. Uma trajetória linear, descreve Dyke (2006), seria aquela em que após a graduação o candidato à vaga de professor obtenha um mestrado, seguido de um doutorado sem interrupções, e, enfim, um posto como professor. Todavia, esse percurso há muito deixou de ser a norma. Após a obtenção do doutorado, o processo de inserção profissional (obtenção de um vaga como professor e obtenção da permanência) pode levar ainda alguns anos. Esse longa trajetória, normalmente estressante, do acesso à profissão pode passar, segundo Dyke, por uma acumulação sucessiva de pós-doutorados, por uma acumulação de charges d'enseignement (contratos como encarregado de ensino, às vezes durante 5 ou 10 anos, dependendo dos casos), por um estatuto de professor convidado ou substituto, ou ainda, por diversos contratos como pesquisador (vinculado a centros de pesquisa ou a projetos subvencionados), até que o futuro recruta seja selecionado em um concurso como professor. Note-se que alguns professores alegam terem passado por mais de um concurso e até 18 entrevistas antes de terem sido contratados para o emprego atual.

Rev. Diálogo Educ., Curitiba, v. 10, n. 29, p. 59-84, jan./abr. 2010 


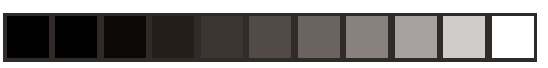

76

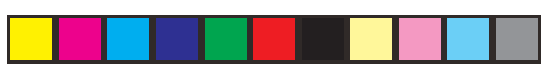

BORGES, C.

Quanto ao processo de contratação, muitos deploram a morosidade do processo, especialmente quando a posse no novo emprego implica a mudança da família de uma cidade para outra, implicando até, em alguns casos, mudança de um país para outro. A morosidade administrativa pode comprometer também a comunicação do professor com o seu antigo empregador, em caso de rescisão de um contrato precedente. A morosidade incide igualmente no período de contratação. Se esta é feita tarde, nas férias, sobra pouco tempo de preparação do professor para assumir as tarefas de ensino (em caso de cursos jamais ensinados especialmente) e de pesquisa, notadamente preparar um pedido de subvenção. Outro problema identificado pelos participantes do estudo é a acolhida no meio universitário. Raras são as universidades que realizam atividade de acolhida aos professores novos, alguns relataram não terem sido recebidos nem pelos diretores de unidade e nem pelos diretores de departamento e sim por colegas! Outros, pelo atraso na contratação, assumiram a vaga após a realização da atividade de acolhida na universidade, ocorrida no início do ano letivo. O conhecimento da organização e estrutura universitária veio então com a experiência, por ensaio e erro.

Enfim, após este longo e estressante processo até a obtenção do posto como professor e subsequente contratação, outro período de estresse e de sobrecarga de trabalho começa com os primeiros anos da inserção profissional, sendo que o primeiro ano é considerado extremamente intenso. Alguns professores alegam trabalharem mais de 15 horas por dia, todos os dias da semana!

Mas a maneira como cada professor vive esse período estressante e de intensa atividade profissional pode variar muito de um professor para outro. Das entrevistas coletivas (grupo focal) realizadas por Dyke (2006), três tipos de inserção foram identificados: inserção fácil, inserção laboriosa e inserção intransponível.

\section{A inserção fácil}

A inserção fácil no departamento e ou faculdade, tem como características:

- o professor já fez o doutorado na universidade onde foi contratado, ele conhece o departamento, os colegas e o meio

Rev. Diálogo Educ., Curitiba, v. 10, n. 29, p. 59-84, jan./abr. 2010 

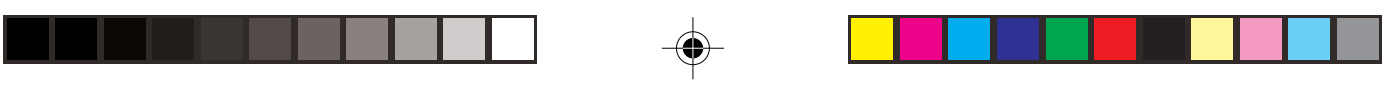

A docência universitária do ponto de vista do trabalho e do recrutamento de novos professores na era atual em Quebec

de trabalho. Ou, o doutorado foi feito no exterior e a expertise do professor é atraente aos olhos dos colegas, além disso, o professor recebe um suporte da instituição universitária para sua instalação (auxílio mudança, ajuda para encontrar um apartamento, escolher a escola para os filhos, etc.);

- o professor já conhece as disciplinas que tem de assumir (já ensinou essas mesmas disciplinas) ou foi assistente de pesquisa no departamento;

- o professor recebe um financiamento superior a 10.000 dólares para iniciar seus projetos de pesquisa e de ensino;

- o professor sai para fazer um pós-doutorado no exterior sabendo que uma vaga está lhe esperando no momento do seu retorno;

- o professor é contratado rapidamente, o ambiente de trabalho é acolhedor e caloroso, o ambiente é positivo, e o enquadramento é feito pelo colegas ou subgrupo de colegas;

- o professor focaliza suas atividades em uma tarefa principal (ensino ou pesquisa) a cada etapa e o diretor de departamento faz com que o este seja poupado da participação em comitês ou de tarefas administrativas;

- o professor já foi contratado de outras universidades e goza de uma larga experiência, o que facilita o seu conhecimento das exigências do trabalho universitário. Além disso, este não tem filhos com menos de 10 anos.

\section{A inserção laboriosa}

Corresponde em termos de características:

- a uma trajetória profissional com muitas mudanças anteriores e contatos com vários meios universitários onde o professor foi contratado em situação de precariedade no emprego, além de uma morosidade no processo de contratação;

- a uma instabilidade organizacional do departamento onde o professor foi engajado (mudança de diretor, ausência de suporte, ou colegialidade entre professores, tensão entre os colegas);

Rev. Diálogo Educ., Curitiba, v. 10, n. 29, p. 59-84, jan./abr. 2010 


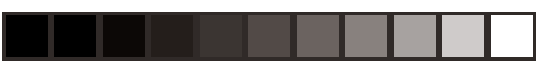

78

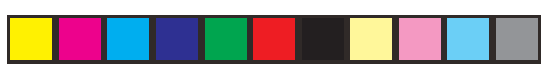

BORGES, C.

- a uma sobrecarga de ensino nos primeiros anos e vários cursos diferentes, corte de estudantes que ultrapassa a média, assim como nenhuma liberação para iniciar-se na pesquisa;

- à ausência total de suporte financeiro para iniciar a pesquisa;

- à família, que se encontra sob dependência total do professor, com filhos pequenos, isto é, ou o parceiro do professor ou professora não trabalha para se ocupar dos filhos ou trata-se de um caso de família "monoparental".

\section{Inserção intransponível}

A inserção intransponível consiste em um processo no qual:

- a contratação foi longa, o processo de concurso foi considerado nebuloso e isso foi expressado ao professor no momento de sua contratação;

- a convenção coletiva não é respeitada, ou seja, as regras definidas entre o sindicato dos professores e a universidade são desrespeitadas em relação ao número de disciplinas atribuídas ao professor, à não liberação para a pesquisa, entre outros aspectos;

- existem grandes tensões no departamento, ou unidade onde o professor foi contratado, não havendo nenhuma ou pouca colegialidade entre os professores.

- ausência de um fundo de apoio à pesquisa e ao ensino para começar na carreira, ou candidatura recusada do professor em um fundo interno de apoio docente;

- sobrecarga de trabalho pesada, nenhum tempo ou pouquíssimo tempo para a vida familiar. Saúde precária que declina com o excesso de trabalho. Necessidade de entrar com licença de saúde.

Como se pode ver, a forma como cada professor novo vive a sua inserção profissional pode variar muito, de um contexto para outro, mas as condições oferecidas pelos departamentos especialmente quanto ao clima de trabalho e quanto ao suporte financeiro e logístico influem definitivamente neste processo. Ficar ou abandonar a profissão? Esta questão permeia o

Rev. Diálogo Educ., Curitiba, v. 10, n. 29, p. 59-84, jan./abr. 2010 
A docência universitária do ponto de vista do trabalho e do recrutamento de novos professores na era atual em Quebec

discurso dos professores, especialmente aqueles que vivem uma inserção instransponível e mesmo os que vivem uma inserção laboriosa.

Complementando a categorização precedente, os pontos de tensão mais cruciais, influindo nesse processo, segundo os professores novos do estudo de Dyke (2006), são principalmente:

a) o equilíbrio entre as diferentes tarefas, em especial, entre pesquisa e ensino;

b) o financiamento para a pesquisa;

c) os critérios de avaliação e de reconhecimento docentes;

d) e a conciliação trabalho-família.

\section{O ponto de vista dos diretores de departamentos}

Se as respostas dos professores novos participantes do grupo focal são contundentes, interessante é compará-las com o resultado das entrevistas realizadas com diferentes diretores de departamentos (de Universidades com mais de 500 professores). Segundo estes, o perfil dos candidatos a um posto de professor evoluiu muito em relação às últimas décadas e, de acordo com o Conselho Superior de Educação (2003), as exigências no momento da contração vão aumentar. Os novos professores deverão desenvolver rapidamente um programa de pesquisa subvencionada, dominar a cultura organizacional da instituição e de sua unidade, e satisfazer as exigências em relação à qualidade de ensino da instituição.

Nesse sentido, $84 \%$ dos diretores consideram que publicação de artigos em revistas científicas é a exigência mais frequente no momento de avaliar um dossiê de um futuro candidato. 80,6\% consideram que o professor deve ser um expert em um campo de pesquisa particular. $75,3 \%$ julgam que o professor tem de mostrar sua capacidade em obter um financiamento de pesquisa. 57\% consideram a capacidade de supervisionar estudantes em pesquisa, outros 54,6 a capacidade de ensinar nos três ciclos universitários. E ainda, 70\% estão satisfeitos com os professores novos, mas insatisfeitos com os candidatos que têm se apresentado nos últimos concursos, particularmente quanto à experiência anterior do candidato.

Enfim, metade dos diretores declaram encontrar certa dificuldade em preencher uma vaga, em função da inexistência de candidatos habilitados

Rev. Diálogo Educ., Curitiba, v. 10, n. 29, p. 59-84, jan./abr. 2010 
a exercer o posto oferecido, em primeiro lugar, e bem mais longe, por motivos de desistência ou abandono, compressões financeiras e falta de atrativos. Certos diretores apresentam como estratégias para paliar esse problema o apoio financeiro a projetos de pesquisa, a valorização de centros e de grupos de pesquisa, a liberação do docente ou a diminuição da sua carga de trabalho. Outros proposições têm sidoigualmente discutidas, como salários mais competitivos, compensação salarial, etc. Os diretores consideram ainda que a formação doutoral e pós-doutoral vai continuar a ser importante no momento da contratação. E as exigências aumentarão quanto: à escolaridade, à autonomia para fazer pesquisa ou capacidade de obter um financiamento, à capacidade de trabalhar em equipe e em colaboração com parceiros externos em pesquisa, à capacidade de valorizar os trabalhos de pesquisa visando sua aplicação no meio, à capacidade de difusão dos trabalhos de pesquisa em revistas científicas com comitê de leitura, ao enquadramento de trabalhos de pesquisa nos ciclos superiores, à utilização de TIC (tecnologias de informação e de comunicação) e enfim, à diversificação de meios pedagógicos.

Todos esses dados levam então a crer que, mesmo se a profissão docente nunca tenha sido formalizada, ou definida de maneira explícita, ao ponto de se pensar em um programa de formação específico para docência universitária $^{12}$, o fato é que a realidade do recrutamento de professores insiste sobre qualidades e competências específicas que são cada vez mais acentuadas e para as quais o professor não recebeu nenhuma formação anteriormente. A aprendizagem se faz na prática, em um contexto no qual, e este é o paradoxo, as condições de trabalho e de inserção profissional são dificultadas pela crise de financiamento das universidades.

\section{À guisa de conclusão... encontrar pistas coletivas}

O objetivo deste texto era de abordar a docência universitária do ponto de vista do trabalho e do recrutamento de novos professores na era atual em Quebec. Enquanto professora debutante na carreira em uma

\footnotetext{
12 A autora descarta aqui os cursos de metodologia do ensino superior ou simplesmente de ensino superior que visam preparar os docentes para o ensino universitário. Dyke (2006) se refere particularmente a programas de preparação à organização e vida universitária, como existem em algumas universidades dos Estados Unidos, as quais oferecem uma formação sobre a vida universitária e também sobre as diferentes tarefas acadêmicas.
}

Rev. Diálogo Educ., Curitiba, v. 10, n. 29, p. 59-84, jan./abr. 2010 

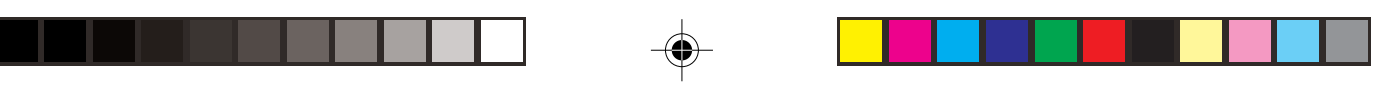

A docência universitária do ponto de vista do trabalho e do recrutamento de novos professores na era atual em Quebec

universidade quebequense, interessou-me particularmente a situação dos professores novos ou debutantes na profissão universitária em Quebec, em particular, e na América do Norte, em geral. Após apresentar algumas estimativas recentes relativamente à renovação dos quadros docentes nas Universidades quebequenses, descrever as transformações do trabalho docente universitário e seus efeitos sobre o docente universitário e particularmente sobre o recrutamento de novos professores, assim como, após relatar o estudo de Dyke (2006), onde são tratados: as preocupações dos professores debutantes (professores novos) assim como a visão dos diretores de departamentos sobre as exigências atuais em termos de contratação de professores, quais aprendizagens ou quais pistas são indicadas em relação a esta problemática?

É importante notar que as pistas possíveis vêm dos próprios professores participantes do estudo realizado por Dyke (2006). Entres estas, destacam-se:

a) em relação à conciliação trabalho-família: medidas de integração dos companheiros e companheiras dos professores, principalmente para facilitar o estabelecimento dos professores em Universidades regionais e melhorar a qualidade da conciliação trabalho-família. Ainda com relação à integração trabalho família, diminuir a carga horária de ensino e não sobrecarregar os professores novos com filhos pequenos com disciplinas à noite e prever um reingresso gradual para a mulheres que retornam de licença maternidade. Além disso, facilitar a criação de creches próximas do trabalho;

b) em relação ao ensino e à pesquisa: garantir um fundo de apoio ao ensino e à pesquisa para os professores novos iniciarem seus projetos de estudo, no caso onde eles são insuficientes ou inexistentes. Não obrigação de fazer um pedido de subvenção já no primeiro ano de trabalho e permitir que o professor focalize, ao menos nos primeiros anos, sobre uma tarefa de cada vez, exemplo: preparação de aulas onde as demandas são urgentes ou preparação de pedidos de subvenção, a fim de desenvolver um determinado campo de pesquisa;

c) em relação às atividades administrativas: nenhuma responsabilidade administrativa, como direção de departamento ou de unidade ou de módulo, etc. Nem participação a comitês de

Rev. Diálogo Educ., Curitiba, v. 10, n. 29, p. 59-84, jan./abr. 2010 


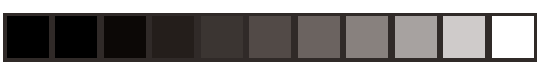

82

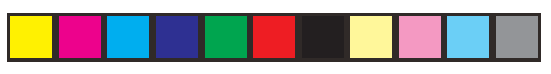

BORGES, C.

estudo ou de outra ordem, já que o professor precisa de tempo para conhecer a instituição e sua cultura de funcionamento;

d) em relação ao conjunto das tarefas docentes: serviço de tutorado, não obrigatório, mas que este seja oficialmente reconhecido, a fim de acompanhar os professores novos nas diferentes tarefas universitárias e facilitar a integração destes aos seus departamentos. Os delegados sindicais, sugerem os professores, poderiam exercer esse tipo de tutorado;

e) e finalmente, em relação aos salários, os professores novos sugerem uma progressão mais rápida na escala salarial, segundo eles, na iniciativa privada os salários evoluem mais rapidamente e são assim mais atraentes.

Os professores novos sugerem assim várias pistas que transcendem as alternativas pontuais que temos observado em diferentes universidades. As sugestões apresentadas convergem também em direção de certas conquistas sindicais, como uma carga de trabalho reduzida nos primeiros anos da carreira, ou seja: duas disciplinas no primeiro ano, três no segundo e carga plena (quatro disciplinas) no terceiro ano. Mas nem todas as universidades adotam essa medida. Outro ponto diz respeito à liberação em caso de obtenção de uma subvenção de pesquisa, nem todas as universidades e mesmo as agências de fomento à pesquisa têm oferecido a possibilidade de redução de carga de ensino, os professores devem assim compor com essa realidade.

Sugestões, embora mais difusas, também foram apontadas em relação à necessidade de reconhecimento das diferentes dimensões da tarefa professoral. Segundo Dyke (2006), os docentes deploram uma visão "maquineísta" e mercantil que a pesquisa tem assumido nas universidades. Eles consideram que é necessário desmistificar os critérios de avaliação docente e melhor preparar os professores novos às etapas avaliativas da carreira universitária. Eles propõem a necessidade de se investir em ambientes de trabalho mais motivadores, alicerçados em um ideal de serviço à coletividade em vistas de uma determinada concepção de universidade a ser alcançada.

Marcante no estudo de Dyke (2006) é também o fato de que os professores novos não se sentem amplamente contemplados pelas lutas sindicais. Alguns consideram que os sindicatos evoluem no âmbito de reivindicações justas, mas que refletem a situação de

Rev. Diálogo Educ., Curitiba, v. 10, n. 29, p. 59-84, jan./abr. 2010 
A docência universitária do ponto de vista do trabalho e do recrutamento de novos professores na era atual em Quebec

professores que já possuem uma estabilidade na carreira, especialmente nas universidades onde existe uma grande decalagem entre os professores novos e os professores mais antigos na carreira. Em geral, eles consideram que o sindicato é importante, mas não veem concretamente sua ação se refletir no quotidiano de seu trabalho. Nesse sentido, uma iniciativa importante foi destacada em relação à Universidade de Montreal, que pediu para seis professores novos, de diferentes áreas, relatarem seu processo de inserção profissional (documento reproduzido em um vídeo à disposição dos professores) entre outras iniciativas.

Embora não tenha sido comentado por Dyke (2006) em seu estudo, é importante sublinhar que várias iniciativas vêm sendo implementadas pelas Universidades no sentido de promover e sustentar o ensino superior ou, em outros termos, a pedagogia universitária. Assim, várias universidades investem cada vez mais em centros ou serviços de apoio docente nos quais se desenvolve todo o tipo de suporte, de formação, de ferramentas para auxiliar os professores na preparação de aulas, na inovação pedagógica, no desenvolvimento de material didático, no conhecimento da clientela estudante atual, na resolução de problemas de ensino. As universidades investem massivamente no mesmo sentido, no suporte à pesquisa, particularmente quanto à preparação de um pedido de subvenção. Essas iniciativas, se bem que louváveis e extremamente pertinentes, não resolvem, contudo, o problema da crise da universidade no seio da Sociedade da Economia e do Saber, para retomar a expressão de Saint-Pierre (2008), nem da lógica mercantil que vem semeando a pesquisa universitária. Este tipo de suporte não resolve, enfim, o problema das transformações pelas quais vêm passando o trabalho docente universitário.

Nesse sentido, e para concluir, vê-se que as alternativas propostas pelos professores novos chegam como um sinal de alerta. Para onde vamos? $\mathrm{E}$ se as exigências tendem a aumentar como indicam os diretores de departamento, que tipo de universidade, ou de professor universitário estaremos construindo? A responsabilidade em relação à produção de conhecimento, assim como com a formação de futuros profissionais passa também pela qualidade das condições de trabalho daqueles que fazem a Universidade. Valorizar a carreira universitária, criar condições de trabalho mais atraentes, e preparar a carreira universitária são alguns dos desafios que devem ser enfrentados nas próximas décadas em Quebec e no Canadá, não somente com vias ao recrutamento de mais professores, mais como uma questão de princípio em relação à Universidade que queremos construir e deixar de herança para as futuras gerações.

Rev. Diálogo Educ., Curitiba, v. 10, n. 29, p. 59-84, jan./abr. 2010 


\section{REFERÊNCIAS}

BERTRAND, D. Diversité, continuité et transformation du travail professoral dans les universités québécoises (1991 et 2003). Conseil supérieur de l'éducation. Québec: Gouvernement du Québec, 2004.

CONFÉRENCE DES RECTEURS ET DES PRINCIPAUX DES UNIVERSITÉS DU QUÉBEC. De la pénurie de professeurs d'université au Québec. Prévisions de la demande de professeurs d'université au Québec jusqu'en 2012. Québec, 2004.

CONSEIL SUPÉRIEUR DE L'ÉDUCATION. Renouveler le corps professoral à l'université: des défis importants à mieux cerner. Québec: Gouvernement du Québec, 2003.

DYKE, N. Renouvellement du corps professoral dans lês Universités em Québec. Profil et expérience de recrues en début de carrière. Fédération Québecoise de professeures et professeurs d'université. Avril, Québec, Qc, 2006. (Brochura).

ESTATÍSTICA CANADÁ. Où allez-vous docteur? Bulletin de l'analyse en innovation, v. 6, n. 3, p. 5, 2004.

SAINT-PIERRE, C. L'Université dans l'économie et la société du Savoir: une mission sous tension-une nécessité d'innover. COLLOQUE DE LA FÉDÉRATION QUÉBÉCOISE DES PROFESSEURES ETT PROFESSEURS D’UNIVERSITÉ (FQPPU). 6 -7 novembre. Paper. 2008. Não publicada.

Recebido: 06/11/2009

Received: 11/06/2009

Aprovado: 03/12/2009

Approved: 12/03/2009

Rev. Diálogo Educ., Curitiba, v. 10, n. 29, p. 59-84, jan./abr. 2010 